\title{
Fibronectin synthesis in subretinal membranes of proliferative vitreoretinopathy
}

\author{
P Hiscott, H A Waller, I Grierson, M G Butler, D L Scott, Z Gregor, I Morino
}

\begin{abstract}
In situ hybridisation and immunohistochemical studies were conducted on six surgically excised subretinal membranes of proliferative vitreoretinopathy to investigate whether displacement of retinal pigment epithelial and glial cells to subretinal membranes was associated with fibronectin production by the subretinal membrane cells. Fibronectin messenger RNA (mRNA) and fibronectin immunoreactivity were observed in some cells in all of the subretinal membranes studied and up to $30 \%$ of the cells in individual specimens showed intense labelling for fibronectin mRNA. The results support the concept that the cells in subretinal membranes produce fibronectin. Locally produced fibronectin may play a role in subretinal membrane cohesion, and displacement of retinal pigment epithelial and glial cells from their normal location may induce the cells to manufacture fibronectin. Fibronectin production may be more prominent in migrating subretinal cells.

(Br F Ophthalmol 1992; 76: 486-490)
\end{abstract}

Proliferative vitreoretinopathy (PVR) is a complication of retinal detachment and is characterised by the development of contractile, scarlike fibrocellular membranes on either side of the detached neuroretina (epiretinal and subretinal membranes). ${ }^{1}$ The contractile epiretinal and subretinal membranes of PVR have a similar cellular composition, ${ }^{2-4}$ although contractile subretinal membranes appear to have a larger retinal pigment epithelial component and smaller glial component than epiretinal membranes, ${ }^{356}$ and the extracellular matrix of PVR membranes at both sites contains collagens and glycoproteins, including fibronectin. ${ }^{7-10}$ Fibronectin has a number of important biological functions such as a role in cell-cell and cell-substratum adhesion, ${ }^{11-13}$ and the adhesive properties of fibronectin may contribute to the cell-cell and cell-extracellular matrix cohesion in early PVR membranes.

In PVR, epiretinal glial and retinal pigment epithelial cells are replete with fibronectin messenger RNA (mRNA) whereas cells in the subjacent detached neuroretina and retinal pigment epithelial monolayer exhibit little or no fibronectin message, suggesting that the ectopic retinal pigment epithelial and glial cells produce abundant glycoprotein while those in situ in the retina do not. ${ }^{14}$ The 'up regulation' of fibronectin production by the displaced cells probably contributes to the glycoprotein in epiretinal membranes but the mechanism for the change in gene expression for fibronectin is obscure.

One possible explanation for the activation of fibronectin production in the ectopic cells is that displacement of the retinal pigment epithelial and glial cells from their normal location stimulates, or removes inhibitions from, the cells to produce fibronectin, in which case fibronectin should be produced by the cells supplanted to sites other than the vitreoretinal junction. One such location is within the contractile subretinal membranes of PVR where retinal pigment epithelial and glial cells are displaced into the developing fibrocellular tissue. ${ }^{2-6}$ Therefore, to investigate further the hypothesis that displacement of pigment epithelial and glial retinal cells causes them to produce fibronectin, we examined the cells in PVR subretinal membranes for the presence of fibronectin mRNA employing an in situ hybridisation technique. The results were correlated with the distribution of fibronectin immunoreactivity in the specimens.

\section{Materials and methods}

CONTROL TISSUE

Formalin fixed, paraffin embedded synovial tissues, from patients with rheumatoid arthritis known to contain abundant fibronectin mRNA and show strong fibronectin immunoreactivity, ${ }^{15}$ were used as positive controls for the hybridisation experiments and immunohistochemical procedures.

\section{SUBRETINAL MEMBRANES}

Six subretinal membranes removed during pars plana vitrectomy for PVR were used in the study.

PREPARATION OF SINGLE-STRANDED RNA PROBES

A cDNA clone ( $\mathrm{pFH} 1$ ) representing about one quarter of the estimated size of human cellular fibronectin $\mathrm{mRNA}^{16}{ }^{17}$ was provided by $\mathrm{Dr} F \mathrm{E}$ Baralle, Sir William Dunn School of Pathology, University of Oxford and subcloned into pGEM blue (Promega, WI, USA) to produce singlestranded RNA anti-sense and sense (control) probes, as previously described. ${ }^{14}$ is

Transcription was conducted incorporating digoxigenin-11-UTP (Boehringer Mannheim, $\mathrm{GmbH}$ ) with the standard transcription reaction using SP6 or T7 RNA polymerase (Boehringer). To achieve optimal probe length for tissue penetration alkaline hydrolysis was carried out to give an average probe length of 100 bases. ${ }^{18}$ To prevent digoxigenin loss into the organic phase phenol/chloroform extraction was omitted during probe purification. ${ }^{19}$ To ensure the correct size of transcripts and the success of hydrolysis the probes were checked by $2 \%$ denaturing agarose gel electrophoresis and northern blotting. ${ }^{20}$ Nitrocellulose filters were blocked with 
$3 \%$ normal sheep serum in phosphate buffered saline (PBS; pH 7.4) and subsequent immunochemical detection of probes was carried out using sheep anti-digoxigenin alkaline phosphatase conjugate (Boehringer) at $1: 5000$ in $3 \%$ normal sheep serum/PBS. Development was with NBT/BCIP (Sigma, Poole, UK) in TRIS buffered saline, $\mathrm{pH} 9.5(0.3 \mathrm{mg} / \mathrm{ml}$ NBT; 0.2 $\mathrm{mg} / \mathrm{ml} \mathrm{BCIP;} 0 \cdot 1 \mathrm{M}$ TRIS; $0 \cdot 1 \mathrm{M}$ sodium chloride; $0.005 \mathrm{M}$ magnesium chloride). Probes were stored at $-20^{\circ} \mathrm{C}$ until used.

\section{HYBRIDISATION HISTOCHEMISTRY}

Subretinal membranes were fixed for between 4 and $48 \mathrm{~h}$ in $10 \%$ formol-saline, dehydrated in graded concentrations of ethanol and embedded in paraffin wax.

Sections $(6 \mu \mathrm{m}$ thick) of wax-embedded tissue were cut, dewaxed, permeabilised, treated with proteinase $\mathrm{K}$, post-fixed, dehydrated in methanol and air-dried. ${ }^{14}$ The anti-sense (SP6, fibronectin transcript) probe was then applied at a concentration of 1:100 (approximately $0.1 \mu \mathrm{g} / \mathrm{ml}$ ) in hybridisation medium and the preparations were hybridised overnight under coverslips at $37^{\circ} \mathrm{C}$ in a humid chamber. During all the procedures up to and including hybridisation, RNAse free conditions were employed. ${ }^{20}$ The coverslips and unbound probe were removed as previously described..$^{14}$

Sites of probe binding were visualised immunohistochemically using the antibody to digoxigenin. Non-specific antibody binding was blocked by a 20 minute incubation with $3 \%$ normal sheep serum/PBS, sheep antidigoxigenin antibody-alkaline phosphatase conjugate was applied to the sections for $\mathbf{3 0}$ minutes at a concentration of $1: 200$ in $3 \%$ normal sheep serum/PBS. The sections were washed in PBS and the reaction sites visualised blue/black in colour using NBT/BCIP (as described above) overnight. The preparations were washed, counterstained with haematoxylin and mounted in glycerol.

Procedural controls included (1) pre-treatment of sections with $20 \mu \mathrm{g} / \mathrm{ml}$ RNAse in TRIS/ EDTA buffer $(0.5 \mathrm{M}$ sodium chloride, $10 \mathrm{mM}$ TRIS hydrochloride $\mathrm{pH} 8 \cdot 0,1 \mathrm{mM}$ EDTA) for 30 minutes at $37^{\circ} \mathrm{C}$ to remove all tissue RNA, and (2) incubation of sections with the sense (T7) probe at a concentration of 1:100 instead of the anti-sense probe.

\section{FIBRONECTIN IMMUNOHISTOCHEMISTRY}

Serial sections ( $6 \mu \mathrm{m}$ thick) to those used for in situ hybridisation were immunostained for fibronectin with an antiserum raised in rabbit to human plasma fibronectin (Dako) or a monoclonal antibody from Sigma (which gave similar staining patterns). The immunostaining was conducted as previously described ${ }^{7}$ and the immunoperoxidase technique was used throughout this investigation, employing 3-amino-9ethylcarbazole as chromogen. Some sections were counterstained with Mayer's haematoxylin. Other sections were stained with haematoxylin and eosin. Controls were applied to the immunostaining procedures as previously des- cribed. ${ }^{7}$ In addition, where sufficient tissue was available in the specimens the retinal origin of the subretinal cells was confirmed by immunotyping their intermediate filaments (using glial fibrillary acidic protein to detect glial cells and cytokeratin to demonstrate retinal pigment epithelial cells). ${ }^{2122}$

The hybridisation and immunohistochemical preparations were examined and compared by bright field and differential interference contrast microscopy. Semi-quantitative estimates of hybridisation and immunohistochemical labelling were made by comparing the 'test' sections with controls. Labelling equivalent to that seen in negative controls (for example, sense probe treated sections or immunohistochemical negative control sections) was termed 'background labelling', while positive labelling at a level equivalent to the strongest seen in positive rheumatoid synovium was designated intense
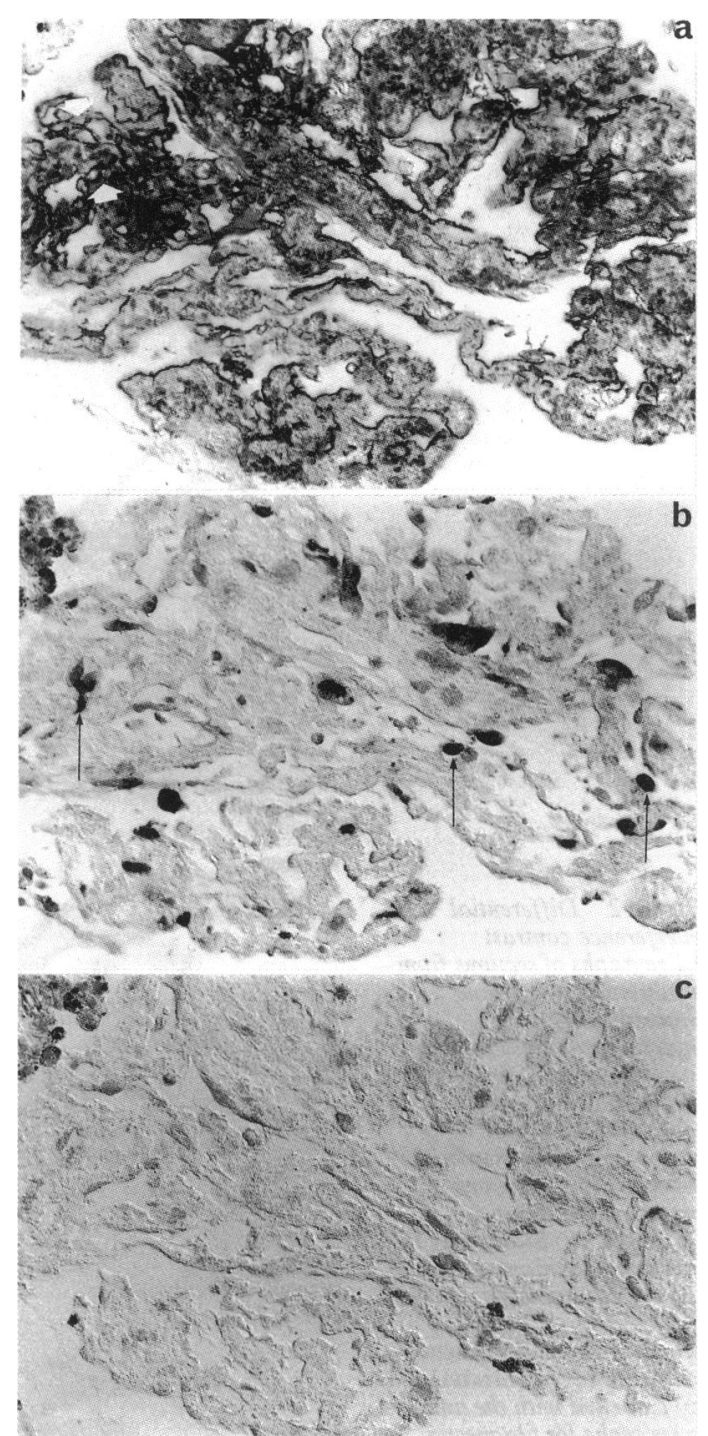

Figure 1 Serial sections from a subretinal membrane seen by differential interference contrast microscopy. (a) Stained with the immunoperoxidase technique for fibronectin (no counterstain). Much of the membrane shows intense fibronectin immunoreactivity with a distinct fibrillar pattern (white arrows). (b) Labelled with the anti-sense probe for fibronectin mRNA and counterstained with haematoxylin. Many of the cells in the section show intense labelling for fibronectin mRNA (black arrows). (c) Labelled with the sense (control) probe. No labelling is seen. A group of pigmented cells is seen in the top left corner. All $\times 230$ 
labelling', Labelling between background and intense levels was called 'moderate labelling'.

\section{Results}

\section{CONTROLS}

Sections of rheumatoid synovium hybridised with the anti-sense probe showed moderate or intense labelling in the synovial lining cells whereas sections hybridised with the sense probe or pretreated with RNAse exhibited only background labelling. The synovium showed moderate or intense immunoreactivity for fibronectin while no immunolabelling occurred in the negative procedural controls. Subretinal membrane sections labelled with the sense probe showed only background labelling levels (Fig 1).

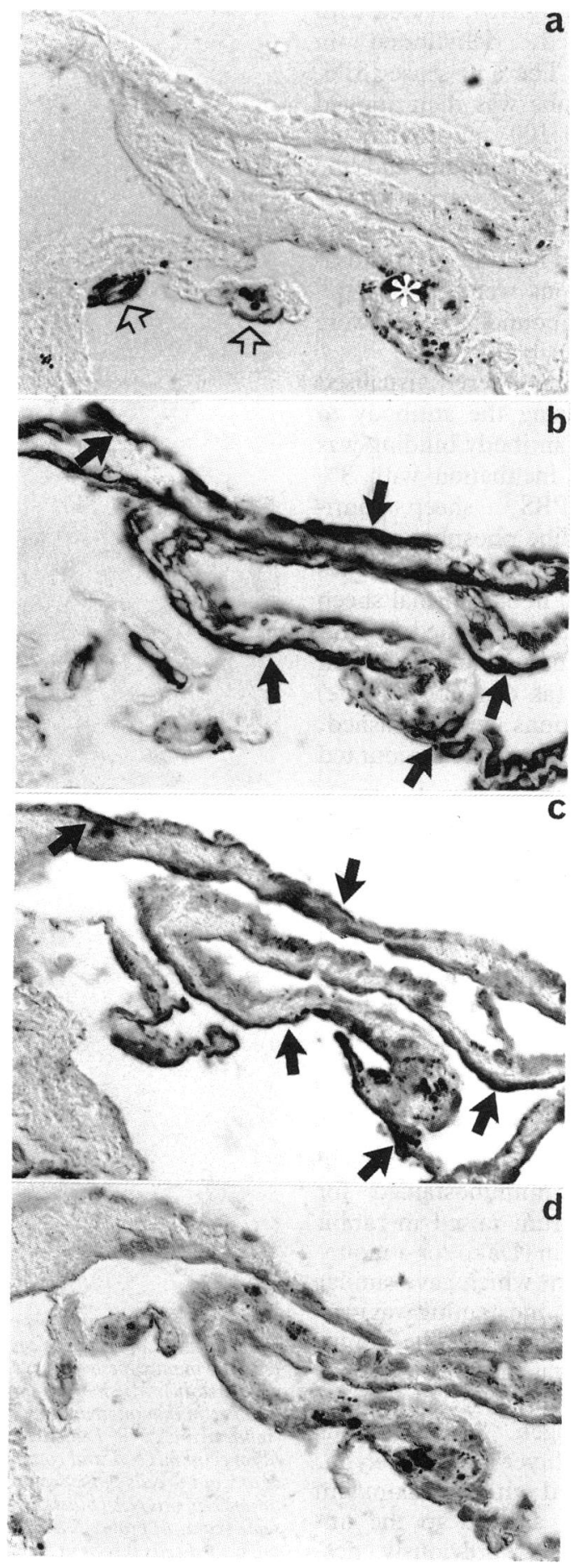

Table 1 Fibronectin $m R N A$ in the cells of PVR subretinal membranes

\begin{tabular}{lll}
\hline & $\begin{array}{l}\text { Proportion of cells } \\
\text { showing moderate } \\
\text { labelling for fibronectin } \\
\text { Subretainal } \\
\text { membrane no }\end{array}$ & $\begin{array}{l}\text { Proportion of cells } \\
\text { showing intense labelling } \\
\text { for fibronectin mRNA } \\
(\%)\end{array}$ \\
\hline 1 & 20 & 0 \\
2 & 20 & 30 \\
3 & 10 & 10 \\
4 & 50 & 0 \\
5 & 30 & 20 \\
6 & 20 & 10 \\
\hline
\end{tabular}

CELLS IN SUBRETINAL MEMBRANES

All six subretinal membranes contained cells which labelled with the anti-sense probe (Figs 1 and 2). There was some variation between the membrane specimens in the numbers of cells which contained fibronectin mRNA. Between $20 \%$ to $50 \%$ of cells showed levels of labelling above background with the anti-sense probe (Table 1). In four membranes between $10 \%$ to $30 \%$ of the total cells in the specimen showed intense labelling with the probe, the remaining positive cells labelling at moderate levels. Labelling was seen in both isolated cells and cells aggregated in layers in the subretinal tissue, including cells in layers at apparent specimen surfaces (Fig 2). Moderate to strong fibronectin immunoreactivity was also observed in all the subretinal membranes (Fig 1). Enough tissue was present in the specimens to confirm that some of the cells which contained fibronectin mRNA were retinal pigment epithelial (four membranes; Fig 2) or glial (one membrane) in origin. It was not possible to detect a quantitative difference between cell types in the intensity of labelling for fibronectin mRNA.

\section{Discussion}

Our results confirm that fibronectin contributes to the extracellular matrix in the contractile subretinal membranes of PVR, demonstrate that many subretinal cells contain mRNA for the glycoprotein, and affirm that cells in subretinal membranes produce fibronectin. Moreover, the results are in keeping with the observation that fibronectin is synthesised by retinal pigment epithelium in vitro, ${ }^{2324}$ since retinal pigment epithelial cells are a major component of subretinal membranes. ${ }^{1-6}$

The production of fibronectin by cells in subretinal membranes represents a marked behavioural change from the activities seen in the cells in situ in attached and even detached adult human retina, since retinal pigment epithelial and glial cells in situ lack appreciable fibronectin immunoreactivity and mRNA. ${ }^{14}$ This 'up regulation' of fibronectin production by retinal pigment epithelial and glial cells in subretinal membranes may be caused by one of several mechanisms. One possibility is that inflammatory mediators within the vitreous and subretinal fluids of eyes developing PVR subretinal membranes, or factors derived from inflammatory cells in evolving membranes, may stimulate fibronectin production. It has been shown that hepatocytes manufacture fibronectin in the presence of interleukin- $6 .{ }^{25}$ However, the apparent absence of fibronectin production in the adjacent

(arrows). (d) Labelled with counterstained with

haemotoxylin. No labelling is seen. All $\times 290$ 
neuroretina and retinal pigment epithelial monolayer is counter to this theory. Alternatively, the observation of fibronectin synthesis in the subretinal, as well as the epiretinal,,$^{14}$ component of PVR is in keeping with the theory that it is the displacement of retinal pigment epithelial and glial cells from their normal location which induces, or removes constraints from, the cells to produce fibronectin.

Some of the fibronectin in subretinal membranes may also be derived from plasma fibronectin, since fibronectin enters the vitreous and subretinal space following breakdown of the blood retina barrier in retinal detachment and PVR. ${ }^{26-28}$ The developing subretinal 'scars' may then incorporate the plasma-derived fibronectin. Indeed, moderate to strong fibronectin immunoreactivity was observed in all the subretinal membranes studied irrespective of the proportion of cells expressing fibronectin mRNA. However, much of the fibronectin content of the membranes is likely to emanate from the subretinal cells themselves since cell surface fibronectin is thought to be insoluble ${ }^{13}$ and therefore is likely to accumulate in the tissue. Thus both plasma and locally-produced fibronectin probably contribute to the tissue.

The accumulation of both plasma and locallyproduced fibronectin has been described in reparative processes elsewhere in the body ${ }^{13} 29$ and in this respect subretinal membrane formation may be likened to an evolving scar. However, in other respects subretinal membranes differ from healing wounds - for example, the absence of a prominent vascular component, ${ }^{6}$ and it remains to be seen whether the fibronectin is as important in subretinal membrane formation as it is wound healing in general.

The production of fibronectin by subretinal membrane cells does not imply that fibronectin is important in the pathobiology of the tissue per se. However, the abundance of message in some subretinal membranes and the recent demonstration of fibronectin receptors on cells displaced into PVR epiretinal membranes ${ }^{30}$ is in keeping with the concept that the glycoprotein plays a role in subretinal membrane development.

In early PVR, plasma-derived fibronectin is likely to be involved in chemotactic recruitment of cells into the developing subretinal tissue. As the subretinal membrane cells themselves begin to produce fibronectin, the insoluble cell surface glycoprotein may contribute to the cohesion of the tissue and potentiate the chemotactic stimulus in the membrane. Indeed, work in our laboratory suggests that retinal pigment epithelial cells may be migrating into already well established subretinal membranes. ${ }^{31} 32$

Migrating cells may not only be attracted into developing subretinal membranes by fibronectin but could specifically be producing the glycoprotein since migratory cells in other pathological tissues can produce fibronectin. ${ }^{33}$ Interestingly, fibronectin mRNA was particularly noted in cells at apparent surfaces of the subretinal membranes where migratory cells may be expected. If migrating cells produce fibronectin in evolving membranes, it is possible that a single agent could prevent both recruitment of cells into and cohesion within developing membranes and provide a new avenue of therapeutic intervention in the process.

This work was funded by the Wellcome Trust (grant no 17095/1.4R) and the Joint Research Board (St Bartholomew's Hospital). Mr R Howes provided photographic help. Dr Scott is Muir Hambro Fellow of the Royal College of Physicians.

1 The Retina Society Terminology Committee. The classification of retinal detachment with proliferative vitreoretinopathy. Ophthalmology 1983; 90: 121-5.

2 Daicker B. Constricting retroretinal membranes associated with traumatic retinal detachments. Graefes Arch Clin Exp Ophthalmol 1985; 222: 147-53.

3 Shirakawa $H$, Yoshimura N, Yamakawa $R$, Matasumura $M$, Okada $M$, Ogina $N$. Cell components in proliferative Okada $M$, Ogina $\mathrm{N}$. Cell components in proliferative
vitreoretinopathy: immunofluorescent double staining of vitreoretinopathy: immunofluorescent double staining of 1987; 194: 56-62.

4 Schwartz D, de la Cruz ZC, Green WR, Michels RG. Proliferative vitreoretinopathy. Ultrastructural study of 20 retroretinal membranes removed by vitreous surgery. Retina 1988; 8: 275-81.

5 Trese MT, Chandler DB, Machemer R. Subretinal strands: ultrastructural features. Graefes Arch Clin Exp Ophthalmol 1985; 223: 35-40.

6 Hiscott P, Morino I, Alexander R, Grierson I, Gregor Z. Cellular components of subretinal membranes in proliferative vitreoretinopathy. Eye 1989; 3: 606-10.

7 Hiscott PS, Grierson I, McLeod D. Natural history of fibrocellular epiretinal membranes: a quantitative, autoradiographic and immunohistochemical study. $\mathrm{Br} \mathcal{J}$ Ophthalmol 1984; 69: 810-23.

8 Scheiffarth OF, Kampik A, Guenther H, v d Mark K. Proteins of the extracellular matrix in vitreoretinal membranes. Graefes Arch Clin Exp Ophthalmol 1988: 226: 357-61.

9 Morino I, Hiscott P, McKechnie N, Grierson I. Variation in epiretinal membrane components with clinical duration of epiretinal membrane components with clinical duration of

10 Okada M, Matsumura M, Hosoda Y, Ogino N, Honda Y. Immunohistochemical identification of the cellular and extracellular components of subretinal proliferative tissues. Invest Ophthalmol Vis Sci 1991; 32(suppl): 857.

11 Yamada KM, Yamada SS, Pastan I. The major cell surface glycoprotein of chick embryo fibroblasts is an agglutinin. Proc Natl Acad Sci USA 1975; 72: 3158-62.

12 Pearlstein E, Gold LI, Garcio-Pardo A. Fibronectin: a review of its structure and biological activity. Mol Cell Biochem 1980; 29: 103-28.

13 d'Ardenne AJ, McGee JO'D. Fibronectin in disease. 7 Pathol 1984; 142: 235-51.

14 Hiscott P, Waller HA, Butler MG, Grierson I, Scott D. Local production of fibronectin by ectopic human retinal cells. Cel Tissue Res 1992; 267: 185-92.

15 Waller HA, Butler MG, McClean JGB, Dowd GSE, Scott DL. The localisation of fibronectin mRNA in the rheumatoid synovium by in situ hybridisation. Br $\mathcal{F}$ Rheumatol 1991; 29(suppl): 36

16 Kornblihtt AR, Vibe-Pedersen K, Baralle FE. Isolation and characterization of cNDA clones for human and bovine characterization of cNDA clones for human and bovine
fibronectins. Proc Natl Acad Sci USA 1983; 80: 3218-22.

17 Kornblihtt AR, Vibe-Pedersen K, Baralle FE. Human fibronectin: molecular cloning evidence for two mRNA species differing by an internal segment coding for a structural domain. $E M B O \mathcal{F} 1984 ; 3: 221-6$.

8 Angerer LM, Stoler MH, Angerer RL. In situ hybridisation with RNA probes: an annotated recipe. In: Valentino KL Eberwise JH, Barchas JD, eds. In situ hybridisation applications to neurobiology. Oxford: Oxford University Press, 1987, 42-70.

19 Schmitz GG, Walter T, Seibl R, Kessler C. Non-radioactive labelling of oligonucleotides in vitro with the hapten digoxigenin by tailing with terminal transferase. Anal Biochem 1991; 192: 222-31.

20 Sambrook J, Fritsch EF, Maniatis T. Molecular cloning - $a$ laboratory manual, 2nd edn. New York: Cold Spring Harbor Laboratory Press, 1989.

21 Hiscott PS, Grierson I, Trombetta CJ, Rahi AHS, Marshall J, McLeod D. Retinal and epiretinal glia - an immunohistochemical study. $\mathrm{Br} \mathcal{F}$ Ophthalmol 1984; 68: 698-707.

22 Hiscott PS, Grierson I, McLeod D. Retinal pigment epithelial cells in epiretinal membranes: an immunohistochemical cells in epiretinal membranes: an imm

23 Campochiaro PA, Jerdan JA, Glaser BM. The extracellular matrix of human retinal pigment epithelial cells in vivo and its synthesis in vitro. Invest Ophthalmol Vis Sci 1986; 27 1615-21.

24 Newsome DA, Pfeffer BA, Hewitt AT, Robey PG, Hassell JR. Detection of extracellular matrix molecules synthesized in vitro by monkey and human retinal pigment epithelium: influence of donor age and multiple passages. Exp Eye Res 1988; 46: 305-21

25 Hagiwara T, Suzuki H, Kono I, Kashiwagi H, Akiyama Y, Onozaki $\mathrm{K}$. Regulation of fibronectin synthesis by interleukin-1 and interleukin-6 in rat hepatocytes. Am F Pathol 1990; 133: 39-47.

26 Campochiaro PA, Jerdan JA, Glaser BM. Serum contains chemoattractants for human retinal pigment epithelial cells. Arch Ophthalmol 1984; 102: 1830-3.

27 Campochiaro PA, Jerdan JA, Glaser BM. Vitreous aspirate from patients with proliferative vitreoretinopathy stimulate 
retinal pigment epithelial cell migration. Arch Ophthalmol 1885; 103: 403-5.

28 Campochiaro PA, Sen HA, Robertson TJ, Conway BP. The role of the breakdown of the blood-retinal barrier in proliferative vitreoretinopathy. emann $\mathrm{P}$, eds. Proliferative vitreoretinopathy. Heidelberg: Kaden, 1989, 45-9.

29 Casscells W, Kimura H, Sanchez JA, Yu Z, Ferrans VJ. Immunohistochemical study of fibronectin in experimenta Immunohistochemical study of fibronectin in experime

30 Weller $M$, Wiedemann P, Bresgen $M$, Heimann $K$. Vitronectin and proliferative intraocular disorders. II. Expression of cell surface receptors for fibronectin and vitronectin in periretinal membranes. Int Ophthalmol 1991; 15: 103-8.

31 Robey HL, Hiscott P, Grierson I. Cytoskeletal reorganisation in mobilised migratory human retinal pigment epithelia cells in vitro. Invest Ophthalmol Vis Sci 1991; 32(suppl): 767

32 Hiscott P, Morino I, McKechnie N, Grierson I, Gregor Z Proliferating retinal pigment epithelial cells in subretinal membranes. Proc XXVI Internat Cong Ophthalmol. Amsterdam: Elsevier, 1991.

33 Adachi K, Yamauchi K, Bernaudin J-F, Fouret P, Ferrans VJ, Crystal RG. Evaluation of fibronectin gene expression by in situ hybridisation: differential expression of the fibronectin gene among populations of human alveolar macrophages. Am F Pathol 1988; 133: 193-203. 